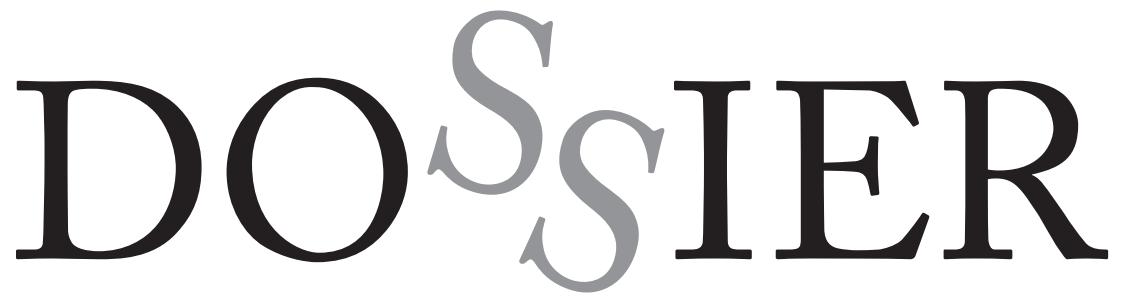

\title{
La traducción \\ de la literatura infantil y juvenil
}

COORDINADORAS

Cecilia Alvstad

Åse JOHNSEN 

de.

TRANS · núm. I8 · 2014

DOSSIER · 11-14

\section{Presentación}

Cecilia Alvstad

Universidad de Oslo

ÅsE JOHNSEN

Universidad de Bergen 
Muchos niños leen por el puro placer de la lectura. Otros leen porque sus padres o profesores consideran que de esa manera aprenderán a usar mejor la lengua o adquirirán conocimientos sobre el mundo. En la literatura infantil, muchos niños hallarán por primera vez el empleo de una variedad de recursos literarios así como ciertas convenciones narrativas como el narrador de primera persona, el discurso indirecto libre y los relatos enmarcados. La literatura infantil puede además ser importante para el desarrollo psicológico y emocional de los niños. En otras palabras, la literatura infantil contribuye a formar a los futuros adultos, incluyendo sus valores éticos y estéticos.

No obstante, los primeros encuentros con nuevos repertorios literarios y culturales no sólo producen placer, también pueden implicar desconcierto. Muchos son los niños que se han quedado confundidos cuando escuchan de un padre que les lee en voz alta un «yo» que claramente no puede ser del padre, sino que necesariamente tiene que ser otro. $\mathrm{O}$ cuando se topan con referencias a personas o fenómenos hasta entonces desconocidos. Pero así adquirimos las convenciones literarias y los repertorios culturales y así las transmitimos a las siguientes generaciones.

El encontrarse con tradiciones o fenómenos desconocidos no es por supuesto algo que sólo les pasa a los niños cuando leen. Los niños (así como los adultos) experimentan procesos similares también fuera del ámbito literario cada vez que se enfrentan a algo nuevo. Sin embargo, lo que es interesante notar, y de hecho lo han señalado muchos estudiosos, es que la literatura infantil y juvenil constituye un producto cultural que generalmente es realizado por adultos (autores, editores, ilustradores y en muchos casos traductores) para que sea recibido por niños; además, prácticamente siempre hay otros adultos (libreros, bibliotecarios, profesores, padres) que funcionan como mediadores entre los emisores adultos y los receptores niños. Por ese hecho la literatura infantil y juvenil se concibe simultáneamente para dos grupos receptores prototípicos. Por una parte, tenemos a los lectores niños, pero, por otra, también a los adultos que funcionan como mediadores, facilitándoles los libros físicamente a los niños y/o leyéndoselos en voz alta. Como las editoriales (y los editores, autores, ilustradores y traductores vinculados a ellas) saben que no dependen solamente de la recepción positiva por parte de los niños, sino también de la de los mediadores, se producen muchas intervenciones en los contenidos y rasgos estilísticos de los libros destinados a niños y jóvenes.

Por lo general no es obvio lo que pueda procesar o no un niño. Si un libro es demasiado avanzado literariamente o si requiere un tipo de conocimiento o madurez del que el niño lector no dispone, siempre hay un riesgo de que quede fuera de su alcance. Esto por supuesto nos puede pasar a los adultos también, pero los niños y jóvenes suelen contar, tal como hemos señalado antes, con más personas que los orienten sobre estos contenidos. Si bien los niños muchas veces son capaces de entender mucho más de lo que creemos, claramente también encontramos límites, tanto en cuanto a lo estilístico como en lo referente al contenido. Hay una serie de cuestiones delicadas como el sexo, la reproducción humana, la religión, el ateísmo, elementos racistas, elementos sexistas, las enfermedades, padres encarcelados, la muerte natural, el suicido, la violencia, el abuso o el incesto que pueden o no aparecer en la literatura infantil y juvenil, pero la variedad entre lo que diferentes mediadores consideran susceptible, aceptable o incluso apto para niños y jóvenes en cuanto a estos temas es, de hecho, enorme, tanto entre individuos, entre generaciones como entre culturas nacionales. 
Que la modulación de la literatura infantil y juvenil existe y es muy activa, queda muy de manifiesto si comparamos lo que se publica como literatura infantil y juvenil hoy con lo que se producía hace cincuenta o cien años. Queda igualmente manifiesto si comparamos lo que se publica como literatura infantil y juvenil en diferentes lenguas y culturas nacionales. Los repertorios se diferencian y esto se ve tanto en el estilo como en el contenido de los libros que se publican. Diferentes sociedades esperan diferentes tipos de conocimientos de sus niños y jóvenes, y está claro que cultivan diferentes aspectos del desarrollo social, emocional y cognitivo de sus niños y jóvenes.

Esta modulación también queda manifiesta en la traducción de literatura infantil y juvenil. Cuando estudiamos lo que se selecciona para ser traducido en diversos contextos y cuando analizamos lo que caracteriza a traducciones para niños y jóvenes (I) en comparación con las traducciones para adultos, (2) en comparación con lo que se publica como literatura infantil y juvenil original en la cultura meta, (3) en comparación con los textos fuente de las traducciones, así como (4) en comparación con las traducciones realizadas de los mismos textos fuente en otras épocas u a otras lenguas quedan expuestos los resultados de la modulación llevada a cabo en cada caso concreto. La traducción por tanto nos ofrece un espacio para mostrar, con ejemplos muy precisos, lo que es característico de la literatura infantil y juvenil en general, pero que no siempre es fácil de probar. Por ese motivo es tan interesante la traducción de literatura infantil y juvenil como objeto de estudio académico.

En este dossier sobre la traducción de literatura infantil y juvenil trataremos diversos tipos de modulación. A continuación presentaremos todas las contribuciones con detalle, pero cabe primero indicar que empezaremos nuestro recorrido prestando atención a la modulación que tiene lugar ya en la selección de los textos para su traducción y en la interacción entre textos traducidos y textos autóctonos en una misma plataforma. Pasaremos luego a una serie de artículos que se centran en diferentes tipos de modulaciones de contenido y de estilo, para terminar con un artículo sobre la literatura infantil y juvenil en la enseñanza de la traducción.

El primer artículo, escrito por Şehnaz Tahir Gürçağlar, trata sobre el habitus de la traducción en Doğan Kardeş, una revista para niños que se publicaba en Turquía entre los años I945 y 1993. Tahir Gürçağlar muestra cómo los contenidos extranjeros se entrelazaban con los autóctonos de la revista, y el destacado rol de los textos que venían de fuera: no todas las traducciones se presentaban como tales, no siempre aparecían mencionados los traductores. Además prueba, y esta es quizás la faceta más interesante de este artículo para el público internacional, la importancia de combinar los estudios de traducción con los estudios periodísticos para poder entender el papel desempeñado por la traducción en determinadas revistas. Esto es importante, ya que las revistas generalmente constituyen una plataforma de introducción muy decisiva para las literaturas extranjeras, no sólo para adultos sino, como demuestra este caso, también para niños.

Continuaremos con un artículo de Lourdes Lorenzo que pone énfasis en el paternalismo traductor, tanto en la traducción literaria como en la audiovisual. Mediante una serie de ejemplos la autora evidencia la frecuencia con la que tanto traductores como otros agentes a lo largo del proceso de traducción cambian, omiten o añaden información para adecuar el texto a los niños lectores meta. La consecuencia es una reducción en la calidad de la traducción que muestra una infravaloración sobre la capacidad del niño para entender tanto aspectos lingüísticos como culturales. 
La autocensura es el tema de la contribución de Nike K. Pokorn quien, con el estado socialista de Eslovenia como telón de fondo, compara dos traducciones de la obra Rolf in the Woods, escrita por Ernest Thompson Seton, uno de los fundadores del movimiento del escultismo norteamericano. En su análisis muestra una serie de diferencias entre la traducción que se publicó antes de la segunda guerra mundial (1938) y la que se publicó después de la guerra (1958), en relación tanto a aspectos político-ideológicos como religiosos. Mediante investigaciones en archivos y entrevistas a personas de la industria editorial de aquel tiempo, el trabajo muestra también que no hubo ninguna censura estatal o institucional en la época, de manera que los cambios encontrados en el análisis deben ser el resultado de la autocensura por parte del traductor.

Tanto el paternalismo como la autocensura son manifestaciones de la voz del traductor o la traductora, y en el presente dossier hay dos artículos que explícitamente trabajan el concepto de voz. Charlotte Lindgren estudia la traducción al francés de cuatro obras de la escritora sueca Moni Nilsson, con especial énfasis en la voz del traductor, estudiando la voz del narrador omnisciente y de los narradores personajes (entre ellos niños) de los libros. Concluye que la voz de los narradores niños es menos marcada en las traducciones que en los originales suecos pero que no desaparece por completo gracias al empleo de ciertas estrategias de traducción.

Carina Gossas y Ulf Norberg estudian la traducción al alemán y al francés de las formas no canónicas del discurso indirecto y de las cursivas empleadas por el autor sueco P.O. Enquist en la novela Den tredje grottans hemlighet $(« \mathrm{El}$ secreto de la tercera cueva»). P.O. Enquist es muy reconocido como escritor para adultos, lo cual puede haber contribuido a cederle espacio para poder utilizar rasgos estilísticos innova- dores y, potencialmente, de difícil comprensión para los lectores niños y jóvenes. En Alemania y Francia no es tan reconocido como en Suecia, y en las traducciones en general se toleran menos innovaciones estilística que en un original, por lo cual es un caso sumamente interesante.

Un desafío con el que se encuentra el traductor al llevar un texto de una cultura a otra es el humor, y es también el caso de muchos textos traducidos para niños y jóvenes. Este tipo de textos supone también un doble desafío, puesto que va destinado tanto a lectores niños como adultos. Mediante el ejemplo de la traducción al español de la obra Charlie and the great glass elevator de Roald Dahl, Elvira Cámara Aguilera pone de manifiesto que la traducción del humor y el juego de palabras, entre otros aspectos, supone un gran desafío en la traducción, sobre todo tomando en cuenta a los lectores niños.

Muchos de los que trabajamos en la investigación de traducción también damos clases en la disciplina, sean clases teóricas o prácticas o, en el mejor de los casos, un compendio de ambas. La combinación de la teoría de la traducción con clases prácticas es el tema del último artículo de este dossier, en el cual Cristina García de Toro plantea una propuesta didáctica para las clases de traducción de literatura infantil y juvenil. La autora subraya la importancia de la teoría y la reflexión sobre el texto que van a traducir los estudiantes, basándose en su propia experiencia del acercamiento por parte de los estudiantes hacia los textos literarios para niños: muchos tienen ideas preconcebidas de que la literatura infantil es una literatura sencilla y que su traducción es fácil, además de que hay que tomar un papel intervencionista para adecuar el texto a los niños lectores. Con esto volvemos al tema del paternalismo en la traducción, y así cerramos este pequeño recorrido por los desafíos y la práctica de la traducción de la literatura infantil y juvenil. 